Published in European Journal of Oncology Nursing, 2019, vol. 39, pp. 81-89 which should be cited to refer to this work DOI:10.1016/j.ejon.2019.01.006

\title{
REVIE $\bigoplus:$ AN INTERVENTION PROMOTING THE DIGNITY OF INDIVIDUALS WITH ADVANCED CANCER: A FEASIBILITY STUDY
}

Maria Goreti da Rocha Rodrigues ${ }^{a}$, Sophie Pautex ${ }^{b}$, Maya Zumstein-Shahac

${ }^{\text {a }}$ HES-SO University of Applied Sciences and Arts Western Switzerland, School of Health Sciences, Geneva, Switzerland

${ }^{\mathrm{b}}$ Sophie PAUTEX, MD, Head of the Geriatric and Palliative Care Community Unit at the University Hospital of Geneva, and Associate Professor at the University of Geneva, Switzerland

${ }^{\mathrm{c}}$ Maya ZUMSTEIN-SHAHA, RN, MSc, PhD, Professor, Bern University of Applied Sciences Health, Switzerland

Corresponding author: gora.darocha@hesge.ch, 47 avenue de Champel ; CH- 1206 Geneva 


\begin{abstract}
Purpose: The dignity of patients is a major concern among health professionals engaged in the care of individuals with advanced cancer. Although several dignity promoting interventions have been developed, none of them have focused on a positive, resourcebased approach. The aim of our study, entitled Revie $\oplus$, was to assess the feasibility and acceptability of a theory-guided life-review intervention, focusing on strength and resources, for patients with advanced cancer and for nurses delivering the intervention.

Method: Our 2015-2016 study was conducted with patients with advanced cancer in an ambulatory and an inpatient setting of a Swiss university hospital. An embedded concurrent mixed method design was used. The feasibility and acceptability of Revie $\oplus$ was explored, as were changes in the sense of dignity, posttraumatic growth, and satisfaction with life.
\end{abstract}

Results: A total of 41 patients received the intervention. The level of attrition was low (26\%). Administering the Revie $\oplus$ intervention proved to be feasible. Participants (patients and nurses) considered the intervention helpful with a high level of satisfaction. A merged data analysis highlighted the need to address the patients' existential concerns. The majority of the participants found that the intervention helped them, and they recommend it for other patients.

Conclusions: This study indicates that the Revie $\oplus$ intervention, which focuses on a resource-based approach, was perceived favorably by all of the participants. A change in the nurse-patient relationship was noted and it was deemed to be beneficial.

Keywords: Dignity, life-review intervention, resource-based approach, feasibility study, mixed method, advanced cancer

\title{
Introduction
}

High levels of existential distress often arise after a diagnosis of advanced cancer, expressed as feelings of helplessness, lack of meaning, discouragement, or remorse (Kissane, 2012). Interventions to relieve existential distress are needed to promote dignity (Institute of medicine, 2013; Miccinesi, Bianchi, Brunelli, \& Borreani, 2012) by achieving existential and spiritual goals, and to consolidate relationships with significant others (Guo \& Jacelon, 2014). Patient dignity is a major concern among health professionals who care for individuals with advanced cancer. This is particularly true for nurses, who are often in close contact with these 
patients and who play a key role in supporting quality of life (Dobrina, Tenze, \& Palese, 2014; Larkin, 2015). Due to a lack of recommendations and guidelines, nurses can feel helpless when confronted with patients' existential concerns (Strang, Henoch, Danielson, Browall, \& Melin-Johansson, 2014). There is ample scope for the development and implementation of nursing interventions in routine clinical practice that are based on a suitable theoretical foundation (Jaiswal, Alici, \& Breitbart, 2014; Johnston et al., 2015; Ostlund, Brown, \& Johnston, 2012).

In current practice, nursing care is generally focused on addressing problems caused by patients' disease and symptoms. Insufficient emphasis is placed on approaches centering on patients' resources and strengths and rooted in positive thinking psychology (Seligman \& Csikszentmihalyi, 2000). Despite the profound challenges of having cancer, some individuals state that the disease also resulted in personal development with changes in their values and their relationship with others. This phenomenon, called Post-Traumatic Growth (PTG) (Tedeschi \& Calhoun, 2004), denotes the positive changes that emerge following a traumatic or stressful event, such as an advanced cancer diagnosis. For individuals facing cancer, the benefits are reported in terms of perceiving being more intensely that is generally manifested in increased personal resources, mainly psychological or spiritual resources, for dealing with the situation. From a social perspective, the noted benefits consist of heightened affection for loved ones as well as stronger and deeper human relationships (Jim \& Jacobsen, 2008).

Life review interventions have been proposed to support the person in this potentially onerous retracing of their identity (Donato, Matuoka, Yamashita, \& Salvetti, 2016; Fitchett, Emanuel, Handzo, Boyken, \& Wilkie, 2015; Keall, Clayton, \& Butow, 2015). This type of intervention for individuals with an incurable disease contributes to decreased depression (Chan, $\mathrm{Ng}$, Tien, Man Ho, \& Thayala, 2013), improved quality of life and spiritual well-being, as well as reduced anxiety (Ando, Morita, Akechi, \& Okamoto, 2010). Dignity therapy (DT) - a lifereview intervention based on a psychological model of dignity (Chochinov et al., 2005) demonstrated a positive impact on quality of life, well-being, sense of dignity (Chochinov et al., 2011), depression and anxiety (Juliao, Oliveira, Nunes, Carneiro, \& Barbosa, 2017). DT also improved perception of the process as experienced by the patient's family (Chochinov et al., 2011; Hack et al., 2010; Hall, Goddard, Speck, Martin, \& Higginson, 2013).

Life review can offer existential benefits. To date, no study with individuals with advanced cancer has used a positive approach centered on personal development and based on a theoretical nursing framework. Such a framework provides a specific perspective on health 
and nursing (McEwen \& Wills, 2011). A framework is needed that supports dignity and related interventions from a nursing perspective. In this study, such a framework was developed by linking Newman's grand theory of Health as Expanding Consciousness (HEC) (Newman, 1994) with Shaha's middle range theory of Omnipresence of Cancer (OC) (Zumstein-Shaha \& Cox, 2017, Shaha, 2014). The "Integrative Theorizing" methodology (Kolcaba \& Kolcaba, 2011) was used for this purpose. This method compares aims and main concepts of the two theories to be linked. By drawing a Venn diagram (Figure 1), the common elements are identified and the unique and original identities of the two theories are retained (Appendix 1). The HEC focuses on change and transformation induced by the experience of illness, i.e., expanding awareness through the disease and includes two major concepts: pattern and consciousness. Pattern refers to a person's unique and distinguishing characteristics determining identity and uniqueness. With these concepts, the HEC offers a holistic view of a person's health. Furthermore, the OC is composed of three main concepts: (a) Toward Authentic Dasein, (b) Mapping Out the Future and (c) Living with Cancer. Additional concepts are uncertainty as well as transitoriness (refering to a confrontation with the transitory nature of life and the resulting anxiety). Each theory, the HEC and the OC, covers part of the phenomenon of dignity in patients with advanced cancer.

Based on the combined theories, an intervention entitled Revie $\bigoplus$ was developed. It allows specialist nurses to discuss life events, to identify the significant elements in patients' life course, and to explore how the diagnosis has changed their values. The intervention focuses on patient's resources changes in relationships with significant others, i.e., persons the patient considers important and significant. Revie $\bigoplus$ aims for patients to discover their potential, to identify strategies for coping with the events, to achieve a better understanding of themselves, and to discuss ultimate life goals or projects (Figure 2, Appendix 2).

The intervention consequently may result in patients developing a higher level of consciousness. Emphasis is placed on significant life events, the emergence of the disease, and its impact on the construction of self, relationships with others, and the redefinition of new values (Shaha, 2014), as well as with reassessing what is most important (Newman, 2008). The intervention invites nurses to listen openly - by being genuinely and fully present - to their patients' stories. Nurses witness these stories and provide feedback in the form of a personalized summary booklet (Newman, 2008). With this type of intervention, the individuals are not seen as problems that need to be resolved. Rather, patients are viewed as whole entities that are constantly evolving (Newman, Smith, Pharris, \& Jones, 2008). 
This theory-guided intervention is person centered and consistent with patient needs, values, and preferences. Directing the intervention to include a positive approach, namely by expanding on the positive changes from the cancer experience, can contribute to promoting dignity, personal development, and a higher degree of overall life satisfaction.

\section{Aims and objectives}

The overall aim of this study was to determine the feasibility of Revie $\bigoplus$ for patients with advanced cancer within the ambulatory and inpatient setting of a university hospital in the French-speaking part of Switzerland. Another aim was to identify potential changes in dignity, posttraumatic growth, and satisfaction with life (Da Rocha Rodrigues, Pautex, \& Shaha, 2016).

The main objectives were:

1. Determine recruitment and retention rates and identify the best strategies for recruitment and retention in the target patient population.

2. Assess the acceptability of the intervention for patients and nurses, in terms of engagement and compliance; assess perceptions regarding barriers and facilitators, the degree of satisfaction and the intervention perceived relevance.

The secondary objectives were to assess the impact of Revie $\bigoplus$ on dignity, posttraumatic growth, and satisfaction with life for patients with advanced cancer.

\section{Method}

A feasibility study was performed using a mixed method approach, i.e., an embedded concurrent design (Creswell, 2014). This design is recommended when gathering information about the feasibility of a new intervention (Craig et al., 2013). The combination of quantitative and qualitative data provides a better understanding of the phenomenon, the different components of the framework, and the process being studied. The quantitative part of the study involved a single group, pre- and post-intervention. The qualitative part was nested within the quantitative part to obtain data on participants' experiences and views (Figure 3).

Inclusion criteria were: adults with (a) advanced cancer, (b) an adequate health status determined by a nurse and a physician, and (c) the ability to cognitively understand and consent to the study. Patients with cognitive disorders related to memory loss or a speech 
impairment were excluded, as were individuals whose command of the French language was insufficient to complete questionnaires. Further details of this study (e.g. the recruitment procedure, training for the intervention) are in our previously published protocol (Da Rocha Rodrigues, Pautex, et al., 2016).

The intervention was deemed to be feasible if 40 participants were recruited over a 12 -month period and if $80 \%$ of them completed the follow-up. A sample size of $20-40$ persons is adequate for a pilot study employing a single group to ultimately estimate the sample size for a future trial (Hertzog, 2008; Thabane et al., 2010). Quantitative and qualitative feasibility data relating to the process, resources and scientific elements of the trial were collected for the patients and for nurses with training and experience in the use of the intervention. We wanted to identify the barriers and the facilitators at all stages (during recruitment, involvement, and termination of the intervention) and understand the potential effects (willingness, adhesion, unanticipated experiences during the trial, resources that can facilitate the intervention). In addition, it was important to determine the patients' and nurses' perceptions and satisfaction with the intervention. Finally, we aimed to determine the appropriateness of the outcome measures and to identify the adequacy of time, location, and process, especially in the field of palliative care research. This field is where all these points can be more difficult, and it was important to explore the emotions associated with this intervention by discussing this intimate and sensitive topic.

Approval for the study was obtained from the Cantonal Commission of Ethics of Scientific Research, Geneva. All patients were provided written informed consent.

\section{Intervention}

The intervention Revie $\bigoplus$ was delivered by eight trained nurses certified in oncology or palliative care. The intervention comprised two separate sessions that took place over the course of one week to 30 days. The first session ( $\mathrm{M}=46 \mathrm{~min})$ comprised a face-to-face meeting conducted by the intervention nurse. The second session $(\mathrm{M}=20 \mathrm{~min})$ was conducted by the researcher, and it allowed for presentation of the booklet to the participant and any changes required to better match the final production with the patient's wishes (Figure 2).

\section{Measurements/data collection}

At the end of the intervention, an acceptability questionnaire about (a) commitment and compliance regarding the protocol (b) any perceived barriers and facilitators, (c) the 
degree of satisfaction, and (d) relevance of the project. The responses were based on a 5-point Likert scale.

Outcome measurements included the Patient Dignity Inventory (PDI) (Chochinov et al., 2008), the Post-Traumatic Growth Inventory (PTGI) (Tedeschi \& Calhoun, 1996), and the Satisfaction with Life Scale (SWLS) (Diener et al., 1985). Semi-directed and tape-recorded interviews were conducted with the patients. Diaries and a focus group interview were used to explore the nurses' acceptability (Figure 4).

\section{Statistical analysis}

\section{Quantitative data}

Analyses were carried out for all patients on available data at baseline and at the end of the study. Data were summarized with standard descriptive measurements. Paired t-tests were used when the data approximated a normal distribution and Wilcoxon signed-rank tests were used for non-normal distributions. Statistical significance was set at $p<0.05$. Statistical Package for the Social Sciences (SPSS) Version 22 software was used.

\section{Qualitative analysis}

Patient interviews and the nurses' focus group were transcribed verbatim. MAXQDA version 12 software was used. An inductive thematic analysis was carried out by two researchers employing independent codification of the verbatim transcript. After pooling, the two coders and an expert discussed and agreed upon the identified themes and subthemes.

\section{Results}

\section{Feasibility}

Between April 2015 and April 2016, study participation was proposed to 103 individuals who met the inclusion criteria. About half $(n=53)$ declined to participate. The main reasons were: inopportune time $(n=6)$, feeling too sad $(n=2)$, not wishing to share their life story $(n=6)$, no particular reason $(n=39)$. Of the 50 individuals who accepted, nine failed to undergo the full intervention. Principal reasons for interrupting included deterioration in overall health $(n=7)$ and death $(n=2)$. A total of 41 patients $(82 \%)$ underwent the intervention (31 outpatients and 10 inpatients).

Summary demographic data are presented in Table 1. Primary tumor sites were gastrointestinal (46\%), lung (22\%), head and neck (12\%), and various other $(20 \%)$ solid 
tumors. On average, about one year had passed since diagnosis, while $29 \%$ had received this announcement in the past six months and $17 \%$ more than five years ago.

Per person and on average, about 30 days passed for the whole intervention. The booklet included photographs, excerpts from poems, prayers, songs, or images representing the interview highlights. Sometimes, personal messages were addressed to significant others.

\section{Acceptability from the patients' perspective}

Five participants were unable to complete the acceptability questionnaire due to a decline in their overall condition. The means and SD for the acceptability of the intervention are presented in Table 2. Regarding the acceptability of the process, the questions addressed during the intervention were deemed pertinent and only slightly upsetting or intrusive (75\%). Most patients (83.3\%) found the intervention helpful. Almost all (97.2\%) were satisfied with the intervention and would recommend it to other patients $(88.8 \%)$.

\section{Qualitative findings}

For the qualitative part, the desired sample size corresponded to achieving data saturation. However, the interview was proposed to all participants. Due to conflicting dates, four persons were unable to participate.

Six major themes emerged from the semi-directed interviews $(n=32$ patients):

1. A good idea. Focusing on positive change despite the cancer experience was appreciated.

"It' is important because we often forget that, yes it's an illness, it's overwhelming, it's all things, but there are also positive aspects that we have to let out!".

Patients experienced changes shortly after the diagnosis. For some, it was learning to enjoy every moment of life with greater intensity. Patients described how they used their own resources to cope with the situation and how they redefined their personal relationships.

2. A flood of emotions. Participants were sometimes overwhelmed by their emotions. They referred to "submersion, release of emotions, surprise, a touching moment, joy," and "sadness". Some felt joy and sadness at the same time:

"I cried, I laughed, it was a mixture of emotions, it was... I had to talk about the painful things in my life."

"when you start talking about your husband who is no longer there, children, little children, yes... it's always emotional moments." 
Completing the intervention facilitated emotional release.

"The moments were quite emotionally charged, so it had to come out, too."

3. Individual process. Patients were asked to recall their past and take a step back from the present situation, i.e., to contribute directly. For example, by searching for photographs, or some text. Usually, patients provided these additional pieces after the first session of the intervention.

"It forced me to put into words what I know inside. That it's another step. And it's true that putting it in words, sometimes, it's still different, it's like singing loudly and singing in your head".

"Then after I thought it's still uh, it plunged me into pictures that I had not watched. I was on the computer and then I looked at those pictures."

4. Personal gain. Participants benefitted from the project. They particularly enjoyed the booklet presentation and emphasized the importance of finding their own words.

" All the people I met before, who spoke with me, uh... the thing that touches me the most is that, I'm sure, that it helps me a lot with my illness."

5. Leaving a legacy. For patients receiving the booklet was like being given a gift. The booklet was an opportunity to share with significant others.

"From time to time it also allows us to see, to show, and here it is in writing. The writings, well, they remain".

"And then I'll say it, maybe it's something that's left for my kids, all that"

"I find, there is no need to write a novel, it is only needed that the person who reads it says: well, I recognize mom, I recognize Lydia”.

6. Changing relationship with the nurse. Because of the intervention, a bond of trust was created between patients and nurses.

"So it's nice to be able to share a little bit of oneself with the person who follows us and accompanies us... I appreciated not merely being a number. "

The results of the qualitative analysis highlight a potential impact of Revie $\bigoplus$ in terms of the management of emotions and in an individual journey of awareness of a probable end of life through a review of one's life and to leave a trace. Finally, there was a beneficial effect in the perception of the relationship with the nurse. 


\section{Experience of the intervention from the nurses' point-of-view:}

The nurses appreciated the intervention procedure. They experienced more intense relationships with patients.

"These are timeless and rich moments, a lot of intensity through the look, the touch when she holds my hand, an authentic moment."

"I felt like I was coming out of the interview on a cloud, like a beam of light that I could benefit from. I'm grateful to be able to live moments of intense relationship like this."

There was a sense of success and pleasure. Nurses witnessed the patients' lives. Thus, they were able to validate and legitimize the patient experience. Further results regarding the acceptability of the intervention for nurses has been published (Da Rocha Rodrigues, Colin, Shaha, \& Pautex, 2016).

\section{Secondary outcomes}

The secondary objective was to evaluate potential changes in the patients' sense of dignity, posttraumatic growth, and life satisfaction. On average, 21.17 days (SD of 14.35, a minimum of 4 days, and a maximum of 68) separated the pretest from the posttest.

\section{Dignity}

The median for the total score of the PDI and the median of each subdimension (i.e. distress symptoms, existential distress, dependence, peace of mind, and social support) are presented in Table 3. No statistically significant differences between the pre and post measurements were found in the PDI total score and its subdimensions. For all of the dimensions, with the exception of social support, an increase in the score reflects a deterioration.

Score for each item of the PDI were low (Table 4). None exceeded $\geq 3$, which would indicate that the individual was significantly perturbed by their situation. A statistically significant difference was identified for two items: (a) "feeling like I am no longer who I was", with this feeling become more pronounced at T2; and (b) "not feeling supported by my health care providers", reflected a greater perception of support from the care providers.

\section{Posttraumatic growth and satisfaction with life}

Overall, a high level of posttraumatic growth (Table 5) was observed. No statistically significant difference was found in the total PTGI score (range 21 - 126) and its subdimensions (i.e. relationships with others, new opportunities, personal strength, spiritual 
changes, and appreciation of life). A high level of life satisfaction was observed, with a high value for the total SWLS (range 5 - 35).

\section{Discussion}

An embedded mixed method design was used in our study; whereby quantitative and qualitative data were collected simultaneously. The integration of the data was carried out using a "merged data analysis" to cross-check the results (Creswell \& Plano Clark, 2011). A summary in the form of a synoptic cross-tabulation highlighted the main extracts with comparison (concordance and discrepancy) of the data.

\section{Feasibility and acceptability}

The results of this mixed method protocol, support the feasibility of the study. A total of 41 persons participated in the intervention, of which 36 completed all the procedures (quantitative data). The recruitment procedure was successful (49\% acceptance, i.e., 50 persons) and the attrition rate (28\%) was low compared to similar studies (Fitchett et al., 2015; Keall et al., 2015).

Engagement and scheduling. All participants were highly motivated and engaged in the project, making themselves available for at least two meetings. Patients also contributed specific personal items such as photos or text to better illustrate significant events in their lives. The short interval between sessions to ensure completion of the entire intervention was considered adequate by the participants. This is particularly interesting given the potential for deterioration of patients' overall health (Lo et al., 2014).

Our study was conducted by nurses from an inpatient oncology department to facilitate subsequent implementation of the intervention into practice. These nurses are at the forefront of the provision of care. They daily take care of patients with cancer (Keall et al., 2015; Xiao, Kwong, Pang, \& Mok, 2012). One major limitation of life-review interventions is the time required to conduct them. Finding time for this study and conducting the intervention was not perceived as a problem by our participants because the sessions were scheduled according to their routine care appointments.

Barriers, facilitators. The intrusive or upsetting nature of the issues addressed during the sessions could have been a barrier to implementating the intervention. Although patients did not consider the questions intrusive or overwhelming in the questionnaire, the verbatim transcripts highlighted a substantial emotional investment. However, the need to release these 
emotions has been strongly emphasized by patients with life-threatening disease (Institute of medicine, 2013; Xiao et al., 2012). The intervention aimed to value people's resources and focus on positive changes despite the disease. Patients were still using this approach during the final evaluation of the intervention. The identified subthemes reflected the importance given to fully enjoying life. This may have been helpful in dealing with the flood of emotions experienced by the patient. We had not initially thought about an individual strategy to support the patient in managing these emotions; evoking and releasing emotions could possibly be part of personal growth.

In contrast, the majority of the nurses considered the questions to be overwhelming ( $\mathrm{Da}$ Rocha Rodrigues, Colin, et al., 2016). There was often a feeling of submersion. Hence, debriefing moments and support from the care team were essential.

The daily work schedule of nurses can be adjusted to find time for such an intervention. However, rearrangements may be necessary. The layout and printing of the booklets for our study was supported by the first author's institution. The costs of creating the booklet corresponded to those for creating a generativity document in DT. Finalization of the booklet, which includes transcription and editing, took approximately two to four hours, and this corresponded with results of similar research (Fitchett et al., 2015; Johns, 2013).

The satisfaction and relevance. Overall, appreciation for Revie $\bigoplus$ was expressed through satisfaction with the presentation and the content of the booklet (patients and nurses). Both analyses (i.e. quantitative and qualitative) emphasized the benefits of the intervention. The intervention was considered to be helpful. Personal gain was highlighted as well as the opportunity to share moments of joy. The gain for the patient included "having received a gift" that uses their own words and by having something meaningful to share with their loved ones. The booklet signified a possibility of leaving a legacy (Garlan, Butler, Rosenbaum, Siegel, \& Spiegel, 2010; Hall et al., 2013; Xiao et al., 2012). The cancer experience can lead to a change or even a disruption in relationships with the close relatives. Revie $\bigoplus$ is an opportunity for the patient to rethink and define relationships. The booklet also allows the person to give importance to experiences shared with other people. In a further study, it will be necessary to gather relatives' perspectives or even to integrate them into the intervention, if the patient wishes.

All the participants considered Revie $\bigoplus$ to be relevant and they recommended implementation of this intervention in current clinical practice. Focusing on positive changes 
despite the disease and leveraging resources and strengths was appreciated. Similarly, the accomplishment of personal projects was considered helpful.

Finally, the intervention allowed for a transformation of the patient-nurse relationship (Da Rocha et al., 2016). A significant improvement was observed for dignity item "not feeling supported by caregivers". This change was also indicated by the patient narratives as a strengthening of trust, as noted by other studies (Strandås \& Bondas, 2018). Patients expect professionals to have a genuine presence and to show empathy and commitment (Edwards, Pang, Shiu, \& Chan, 2010; Hall et al., 2013).

\section{Secondary outcomes}

No statistically significant improvement in the sense of dignity was discerned, as in other studies using Patient Dignity Inventory (PDI) (Chochinov et al., 2011; Fitchett et al., 2015; Gagnon et al., 2010). A ceiling effect due to the low distress rate of the sample could explain this result (Houmann, Chochinov, Kristjanson, Petersen, \& Groenvold, 2014). Positive results were obtained for patients with high levels of anxiety or depression (Juliao et al., 2017). Given a relatively low level of distress, aiming for stabilization of the score, could be a good compromise for clinical practice beacuse physical and spiritual distress frequently intensifies during disease progression. A limiting factor is that the distressed patients who could benefit most from the intervention are precisely those who have the most difficulty in carrying a heavy burden of disease and are therefore more likely to reject the intervention.

No statistically significant changes in posttraumatic growth was obtained, which corresponded to other studies (Garlan et al., 2010; Lo et al., 2014). The integration of quantitative and qualitative data, however, allowed comparison of the patients' perspective and the various subdimensions of the PTGI scale (i.e., new opportunities, relationship with others, personal strength, appreciation of life, spiritual change) (Moreno \& Stanton, 2013). According to the participants in our study, there is a new level of awareness since the diagnosis (Appendix 3). Values and priorities are revisited, the present is lived more intensely, and there is a new appreciation for life and for the relationships with others.

Despite the distressing experience, patients confronted with a life-threatening illness, were able to attain an overall level of satisfaction with their lives. Our sample exhibited a high value and it did not exhibit a high threshold of suffering, as reflected by the total score for the patient dignity. Life reviews allow the expression of overall satisfaction with life and even 
identification of the elements that disrupt this feeling (Jenko, Gonzalez, \& Alley, 2010; Tarquinio, 2012).

One limitation of our study is the absence of a control group, which would have made it possible to compare the groups in terms of the impact of the intervention's impact. However, the focus of our study was the feasibility of the recruitment process and the procedures as a prerequisite for a larger study. Although the sample favored a feasibility study, it may be that our quantitative results would have been significant with a larger number of participants. To build on this research, we are considering a randomized controlled trial to measure the effectiveness of our intervention. It also seems that the impact of Revie $\bigoplus$ would vary immensely based on when it is done in patients' cancer trajectory. Determining the ideal time will also be considered in the future study.

\section{Conclusion}

Our study aimed to assess the feasibility of the Revie $\bigoplus$ intervention to promote the dignity for patients with advanced cancer and to determine possible changes in sense of dignity, personal development, and life satisfaction. The embedded mixed-method design allowed for broad collecting of information thereby illuminating the complexity of the experiences of patients and nurses.

The results demonstrate the feasibility of the intervention and they indicate a good level of acceptability for patients and nurses. The Revie $\bigoplus$ intervention is innovative because it focuses on strengths, resources, and positive change despite illness rather than deficits and problems. This approach was welcomed by all of the participants, and complements the current state of research in palliative care.

Health professionals can promote the dignity of end-of-life patients by offering a holistic approach that supports people's preferences and values and is systematically integrated into therapeutic care plans as soon as a critical illness comes to light. Reinforcing the feeling of existence is important in regard to an individual's personal identity and life. It is about dignity as an identity, which is specifically related to the relationship with self-identity and the impact of social factors, namely how one is perceived by others (Rodriguez-Prat, Monforte-Royo, Porta-Sales, Escribano, \& Balaguer, 2016). There is a need to be recognized as a unique individual until the end, to not lose one's identity, to be treated with distinction, and to benefit from a positive person-centered approach. 
Acknowledgments: The authors would like to thank the HES-SO University of Applied Sciences and Arts Western Switzerland, School of Health Sciences, Geneva, Switzerland for their valuable contributions.

Conflict of interest: The authors hereby declare that no conflict of interest whatsoever exists regarding the scientific work submitted for publication.

\section{Appendix 1 : combining HEC with OC}

The development of a theoretical framework by linking Newman's grand theory with Shaha's middle range theory in the field of palliative nursing care is proposed so as to guide the development of an intervention for a new research proposal.

We employed the "Integrative Theorizing" methodology (Kolcaba \& Kolcaba, 2011), recommended for linking theories with one another. Heuristic criteria were employed to determine the compatibility: shared assumptions, cultural applicability, disciplinary boundaries, nursing education, focus of care, process or product distinction, shared values, scientific orientation. Once compatibility had been verified, Kolcaba and Kolcaba (2011) recommend constructing a Venn diagram that illustrates how the HEC and the OC intersect. Thus, new insights were obtained.

Newman's Theory of Health as Expanding Consciousness (HEC) was developed in 1986 and focuses on experiences of change and transformation induced by the experience of illness, i.e., expanding awareness through the disease (Newman, 1994). The HEC includes two major concepts: pattern and consciousness. Pattern refers to the unique and distinguishing characteristics of a person that determine a person's identity and uniqueness. In that, the HEC provides a holistic view of a person's health. Consciousness is defined as the ability to interact with the environment. Therefore, consciousness denotes a process of "becoming increasingly oneself, giving more meaning to one's own life, and achieving more of a connection with others and the world in which we live." While interacting with the patient, the nurse adopts an authentic presence. A person-centered, egalitarian relationship is established that allows the person and the nurse to transform. The phenomenon of living with cancer is not specified by the HEC, and recommendations remain general and unspecific. Moreover, the Omnipresence of Cancer (OC) by Shaha (Zumstein-Shaha \& Cox, 2017) has emerged from a series of studies and describes the experience of living with cancer. This theory aims to describe individual psychosocial reactions to cancer within the first year of the 
cancer trajectory and to provide support for the disclosure of a cancer diagnosis (Shaha, 2014; Zumstein-Shaha \& Cox, 2017). The OC is composed of three main concepts: (a) Toward Authentic Dasein, (b) Mapping out the Future, and (c) Living with Cancer. Additional concepts are: (a) uncertainty (associated with the evolution and influence of the disease), (b) the treatment, and (c) future life. Patients experience a transitoriness that represents a confrontation with the transitory nature of life and the resulting anxiety. Finally, there is locus of control that refers to the patients' attitude toward living with cancer, toward family, and toward health professionals. Individuals develop and employ coping strategies to project the future and to launch themselves into new projects. The goal is to improve the person's quality of life. The OC does not comprise the process of expanding consciousness. Each theory, the HEC and the OC, cover part of the phenomenon of dignity in patients with advanced cancer.

The new insights were:

1. Transitoriness and locus of control (OP) are concrete concepts promoting the process of health as Expanding Consciousness (HEC) as part of the particular experience of being confronted with a life-threatening disease.

2. As methodology of practice is proposed: Using authentic presence (HEC) and enabling patients to share significant life events (HEC) to express emotions, and fear of death (OC). Accentuating personal resources helped patients to face the experience (OC), and to regain meaning of life and finitude. Thus, the dignity of patients was promoted (as stated in the aim of the feasibility study for Revie $\oplus$ ). 
The name of the intervention, Revie $\bigoplus$, was chosen with the nurses conducting the intervention. "Revie" (French) is the association of "re-" and "vie" as it includes a life review, a revisiting of life (vie), and a focus on life. Palliative care is often associated with death, but for us palliative care is about life and enjoying life. The symbol $\oplus$ emphasizes the positive approach and highlights that we promote a person's growth and dignity.

The intervention consists of two sessions. The first face-to-face interview (approximately $60 \mathrm{~min}$ and audio-recorded) allows participants to share significant life events, and it supports personal development by focusing on positive changes that have occurred since the cancer diagnosis. Five domains are addressed: (a) a reflection of significant events of the patient's life story; (b) a discussion of the patient's deepest concerns and his/her thoughts about death and dying (transitoriness) (c) a focus on the positive changes that have occurred since the diagnosis; (d) an expression of the patient's values and their relationship with significant others, who could be anyone the patient considers important and significant, such as family, friends, or the proxy; and (e) a discussion of significant issues (i.e., what patients want to communicate to their relatives or, most importantly, determining the project). Throughout the intervention, nurses with an authentic presence value patients' coping strategies, strengths, and resources. The intervention centers on how an experience with cancer changes patients themselves, their life values, and their relationships with others. The tape recordings of the session are transcribed and a booklet is created. Each booklet is personalized by highlighting the patient's unique style as closely as possible with patients' words and expressions.

According to the patients' wishes, texts, poems, pictures, and citations are integrated into the booklet. The second meeting (30 $\mathrm{min})$ is arranged to present the complete and finalized booklet. As a conclusion to the intervention, the patient is provided a booklet recounting the salient features of their life review along with photographs, quotes, and images.

Appendix 3 : Extract of a verbatim during the Revie $\bigoplus$ intervention

Nurse (N) : What would you say that has been important in your life? The accomplishments you are proud of...

Stephanie (S) : Wow, uh... So well where I'm already proud of my children, my two sons.

$\mathrm{N}$ : You have a very strong connection with them, don't you? 
S : Yes, yes, absolutely. Well, I also think it's in relation to the values I've transmitted, respect, all these things that are disappearing a little today, we're going to say, and it's not always obvious either. But it's true that I'm very close, especially with the disease as well.

$\mathrm{N}: \quad$ Did it weld the bonds?

S : $\quad$ Yeah, and they also revealed a side of them that I thought was there, but that stood out. After that, well, what is important is that I take care of my parents, who are also elderly and have health problems, and it's true that with work it's heavy, but I do it with a lot of pleasure.

The disease, what it has changed for me, is that already uh one I discovered my sons, that I would never have thought uh well that they were like that uh... If I suspected but I was surprised. There was this side, I knew he was a responsible person and everything, but he showed me a side that I didn't think he was like that.

And then well after that I said to myself, in fact I know that for years I have been in a spiral of fatigue, stress or the slightest thing takes on proportions. And then, with the disease, I was able to take enough distance to think about how I function, realizing that I was always there for others but never for myself and and that's also the fact of not being attentive enough to my body, of not asking myself too many questions. (...) so now I took a step back and told everyone, there are things that were important to me, it's no longer important at all. Now I'm getting a little selfish, I'm taking some time for myself, which I didn't do at all before. Before I didn't exist, that was all for others. 


\section{References}

Ando, M., Morita, T., Akechi, T., \& Okamoto, T. (2010). Efficacy of short-term life-review interviews on the spiritual well-being of terminally ill cancer patients. Journal of Pain and Symptom Management, 39(6), 993-1002. doi:10.1016/j.jpainsymman.2009.11.320

Chan, M. F., Ng, S. E., Tien, A., Man Ho, R. C., \& Thayala, J. (2013). A randomised controlled study to explore the effect of life story review on depression in older Chinese in Singapore. Health Soc Care Community, 21(5), 545-553. doi:10.1111/hsc.12043

Chochinov, H. M., Hack, T., Hassard, T., Kristjanson, L. J., McClement, S., \& Harlos, M. (2005). Dignity therapy: A novel psychotherapeutic intervention for patients near the end of life. Journal of Clinical Oncology, 23(24), 5520-5525. doi:Doi 10.1200/Jco.2005.08.391

Chochinov, H. M., Hassard, T., McClement, S., Hack, T., Kristjanson, L. J., Harlos, M., . . Murray, A. (2008). The Patient Dignity Inventory: A Novel Way of Measuring Dignity-Related Distress in Palliative Care. Journal of Pain and Symptom Management, 36(6), 559-570. doi:DOI 10.1016/j.jpainsymman.2007.12.018

Chochinov, H. M., Kristjanson, L. J., Breitbart, W., McClement, S., Hack, T. F., Hassard, T., \& Harlos, M. (2011). Effect of dignity therapy on distress and end-of-life experience in terminally ill patients: a randomised controlled trial. Lancet Oncology, 12(8), 753-762. doi:Doi 10.1016/S1470-2045(11)70153-X

Craig, P., Dieppe, P., Macintyre, S., Michie, S., Nazareth, I., \& Petticrew, M. (2013). Developing and evaluating complex interventions: The new Medical Research Council guidance. International Journal of Nursing Studies, 50(5), 587-592. doi:DOI 10.1016/j.ijnurstu.2012.09.010

Creswell, J. W. (2014). Research design : qualitative, quantitative, and mixed methods approaches (4th international student ed.). Los Angeles: Sage.

Creswell, J. W., \& Plano Clark, V. L. (2011). Designing and conducting mixed methods research (2nd ed.). Los Angeles: SAGE.

Da Rocha, M.-G., Pautex, S., Bollondi-Pauly, C., Bruegger, A., Chong, L., Khaled, S., . . Shaha, M. (2016). Le récit de vie du patient: recueil de témoignages des infirmières dans le cadre de Revie $\oplus$. Revue internationale de soins palliatifs, 31, 43-47. doi:DOI 10.3917/inka.161.0043

Da Rocha Rodrigues, M. G., Colin, S., Shaha, M., \& Pautex, S. (2016). The acceptability of the intervention Revie $\oplus$ : the nurses' perceptions and experiences. Recherche en soins infirmiers, 127(4), 55-70. doi:10.3917/rsi.127.0055

Da Rocha Rodrigues, M. G., Pautex, S., \& Shaha, M. (2016). Revie $\bigoplus$ : the influence of a life review intervention including a positive, patient-centered approach towards enhancing the personal dignity of patients with advanced cancer-a study protocol for a feasibility study using a mixed method investigation. Pilot and Feasibility Studies, 2, 63. doi:10.1186/s40814-016-0101-z

Diener, E., Emmons, R. A., Larsen, R. J., \& Griffin, S. (1985). The Satisfaction With Life Scale. J Pers Assess, 49(1), 71-75. doi:10.1207/s15327752jpa4901_13

Dobrina, R., Tenze, M., \& Palese, A. (2014). An overview of hospice and palliative care nursing models and theories. Int J Palliat Nurs, 20(2), 75-81. doi:10.12968/ijpn.2014.20.2.75

Donato, S. C., Matuoka, J. Y., Yamashita, C. C., \& Salvetti, M. G. (2016). Effects of dignity therapy on terminally ill patients: a systematic review. Revista Da Escola De Enfermagem Da Usp, 50(6), 1014-1024. doi:10.1590/S0080-623420160000700019

Edwards, A., Pang, N., Shiu, V., \& Chan, C. (2010). The understanding of spirituality and the potential role of spiritual care in end-of-life and palliative care: a meta-study of qualitative research. Palliative Medicine, 24(8), 753-770. doi:10.1177/0269216310375860

Fitchett, G., Emanuel, L., Handzo, G., Boyken, L., \& Wilkie, D. J. (2015). Care of the human spirit and the role of dignity therapy: a systematic review of dignity therapy research. BMC Palliative Care, 14, 8. doi:10.1186/s12904-015-0007-1

Gagnon, P., Chochinov, H. M., Cochrane, J. P., Moreau, J. L., Fontaine, R., \& Croteau, L. (2010). Dignity therapy: an intervention to diminish psychological distress in palliative care patients. PsychoOncologie, 4. doi:10.1007/s11839-010-0267-1 
Garlan, R. W., Butler, L. D., Rosenbaum, E., Siegel, A., \& Spiegel, D. (2010). Perceived benefits and psychosocial outcomes of a brief existential family intervention for cancer patients/survivors. Omega (Westport), 62. doi:10.2190/OM.62.3.c

Guo, Q., \& Jacelon, C. S. (2014). An integrative review of dignity in end-of-life care. Palliative Medicine, 28. doi:10.1177/0269216314528399

Hack, T. F., McClement, S. E., Chochinov, H. M., Cann, B. J., Hassard, T. H., Kristjanson, L. J., \& Harlos, M. (2010). Learning from dying patients during their final days: life reflections gleaned from dignity therapy. Palliative Medicine, 24(7), 715-723. doi:Doi 10.1177/0269216310373164

Hall, S., Goddard, C., Speck, P. W., Martin, P., \& Higginson, I. J. (2013). "It makes you feel that somebody is out there caring": a qualitative study of intervention and control participants' perceptions of the benefits of taking part in an evaluation of dignity therapy for people with advanced cancer. Journal of Pain and Symptom Management, 45(4), 712-725. doi:10.1016/j.jpainsymman.2012.03.009

Hertzog, M. A. (2008). Considerations in determining sample size for pilot studies. Research in Nursing \& Health, 31(2), 180-191. doi:Doi 10.1002/Nur.20247

Houmann, L. J., Chochinov, H. M., Kristjanson, L. J., Petersen, M. A., \& Groenvold, M. (2014). A prospective evaluation of Dignity Therapy in advanced cancer patients admitted to palliative care. Palliative Medicine, 28(5), 448-458. doi:10.1177/0269216313514883

Institute of medicine. (2013). Delivering High-Quality Cancer Care: Charting a New Course for a System in Crisis. . Retrieved from http://www.iom.edu/ /media/Files/Report Files/2013/Quality-Cancer-Care/qualitycancercare_slides2.pdf

Jaiswal, R., Alici, Y., \& Breitbart, W. (2014). A comprehensive review of palliative care in patients with cancer. International Review of Psychiatry, 26(1), 87-101. doi:10.3109/09540261.2013.868788

Jenko, M., Gonzalez, L., \& Alley, P. (2010). Life review in critical care: possibilities at the end of life. Crit Care Nurse, 30(1), 17-27; quiz 28. doi:10.4037/ccn2010122

Jim, H. S., \& Jacobsen, P. B. (2008). Posttraumatic stress and posttraumatic growth in cancer survivorship: a review. Cancer Journal, 14(6), 414-419. doi:10.1097/PPO.0b013e31818d8963

Johns, S. A. (2013). Translating dignity therapy into practice: effects and lessons learned. Omega (Westport), 67(1-2), 135-145.

Johnston, B., Larkin, P., Connolly, M., Barry, C., Narayanasamy, M., Ostlund, U., \& Mcllfatrick, S. (2015). Dignity-conserving care in palliative care settings: an integrative review. Journal of Clinical Nursing, 24. doi:10.1111/jocn.12791

Juliao, M., Oliveira, F., Nunes, B., Carneiro, A. V., \& Barbosa, A. (2017). Effect of dignity therapy on end-of-life psychological distress in terminally ill Portuguese patients: A randomized controlled trial. Palliative \& supportive care, 15(6), 628-637. doi:10.1017/S1478951516001140

Keall, R. M., Clayton, J. M., \& Butow, P. N. (2015). Therapeutic life review in palliative care: a systematic review of quantitative evaluations. Journal of Pain and Symptom Management, 49(4), 747-761. doi:10.1016/j.jpainsymman.2014.08.015

Kissane, D. W. (2012). The relief of existential suffering. Archives of Internal Medicine, 172(19), 15011505. doi:10.1001/archinternmed.2012.3633

Kolcaba, K., \& Kolcaba, R. (2011). Integrative Theorizing: Linking Middle-Range Nursing Theories with the Neuman Systems Model. . In B. Neuman \& J. Fawcett (Eds.), The Neuman Systems Model (5th edn. ed.). Upper Saddle River: Prentice Hall.

Larkin, P. (2015). A new vision for palliative care: we are ready. Int J Palliat Nurs, 21(4), 159. doi:10.12968/ijpn.2015.21.4.159

Lo, C., Hales, S., Jung, J., Chiu, A., Panday, T., Rydall, A., . . Rodin, G. (2014). Managing Cancer And Living Meaningfully (CALM): phase 2 trial of a brief individual psychotherapy for patients with advanced cancer. Palliative Medicine, 28(3), 234-242. doi:10.1177/0269216313507757

McEwen, M., \& Wills, E. M. (2011). Theoretical basis for nursing (3rd ed.). Philadelphia: Lippincott Williams \& Wilkins. 
Miccinesi, G., Bianchi, E., Brunelli, C., \& Borreani, C. (2012). End-of-life preferences in advanced cancer patients willing to discuss issues surrounding their terminal condition. European Journal of Cancer Care, 21. doi:10.1111/j.1365-2354.2012.01347.x

Moreno, P. I., \& Stanton, A. L. (2013). Personal growth during the experience of advanced cancer: a systematic review. Cancer Journal, 19(5), 421-430. doi:10.1097/PPO.0b013e3182a5bbe7

Newman, M. A. (1994). Health as expanding consciousness (2 ed.). USA: Jones and Bartlett Publishers.

Newman, M. A. (2008). Transforming presence: The difference that nursing makes. Philadelphia: F.A. Davis Company.

Newman, M. A., Smith, M. C., Pharris, M. D., \& Jones, D. (2008). The focus of the discipline revisited. ANS Advances in Nursing Science, 31(1), E16-27. doi:10.1097/01.ANS.0000311533.65941.f1 00012272-200801000-00011 [pii]

Ostlund, U., Brown, H., \& Johnston, B. (2012). Dignity conserving care at end-of-life: a narrative review. Eur J Oncol Nurs, 16(4), 353-367. doi:10.1016/j.ejon.2011.07.010

Rodriguez-Prat, A., Monforte-Royo, C., Porta-Sales, J., Escribano, X., \& Balaguer, A. (2016). Patient Perspectives of Dignity, Autonomy and Control at the End of Life: Systematic Review and Meta-Ethnography. PLoS One, 11(3), e0151435. doi:10.1371/journal.pone.0151435

Seligman, M. E., \& Csikszentmihalyi, M. (2000). Positive psychology. An introduction. Am Psychol, 55(1), 5-14.

Shaha, M. (2014). The Omnipresence of cancer. (Venia Legendi Cumulative thesis in partial fulfilment), Department of Nursing Science, Witten, Herdecke.

Strandås, M., \& Bondas, T. (2018). The nurse-patient relationship as a story of health enhancement in community care: A meta-ethnography. Journal of Advanced Nursing, 74(1), 11-22. doi:10.1111/jan.13389

Strang, S., Henoch, I., Danielson, E., Browall, M., \& Melin-Johansson, C. (2014). Communication about existential issues with patients close to death-nurses' reflections on content, process and meaning. Psycho-Oncology, 23(5), 562-568. doi:10.1002/pon.3456

Tarquinio, C. (2012). Manuel des psychothérapies complémentaires : fondements, mise en oeuvre, cas clinique. Paris: Dunod.

Tedeschi, R. G., \& Calhoun, L. G. (1996). The Posttraumatic Growth Inventory: measuring the positive legacy of trauma. Journal of Traumatic Stress, 9(3), 455-471.

Tedeschi, R. G., \& Calhoun, L. G. (2004). Posttraumatic growth: Conceptual foundations and empirical evidence. Psychological Inquiry, 15(1), 1-18. doi:DOI 10.1207/s15327965pli1501_01

Thabane, L., Ma, J., Chu, R., Cheng, J., Ismaila, A., Rios, L. P., . . Goldsmith, C. H. (2010). A tutorial on pilot studies: the what, why and how. Bmc Medical Research Methodology, 10. doi:Artn 110.1186/1471-2288-10-1

Xiao, H., Kwong, E., Pang, S., \& Mok, E. (2012). Perceptions of a life review programme among Chinese patients with advanced cancer. Journal of Clinical Nursing, 21(3-4), 564-572. doi:10.1111/j.1365-2702.2011.03842.x

Zumstein-Shaha, M., \& Cox, C. L. (2017). A theory of cancer care in healthcare settings (1st ed.). London: Routledge. 
Tables

Table 1. Demographics of the study population. $\mathrm{N}=41$

\begin{tabular}{|c|c|c|c|c|c|c|}
\hline & & $\mathrm{n}$ & $\%$ & Mean & (SD) & range \\
\hline \multirow[t]{2}{*}{ Gender: } & Female & 24 & $(58.5)$ & & & \\
\hline & Male & 17 & $(41.5)$ & & & \\
\hline \multirow[t]{4}{*}{ Education: } & Compulsory & 8 & $(19.5)$ & & & \\
\hline & Post-compulsory secondary school & 15 & $(36.6)$ & & & \\
\hline & High school & 8 & $(19.5)$ & & & \\
\hline & College /university & 10 & $(24.4)$ & & & \\
\hline \multirow{5}{*}{ Professional situation: } & Full-time & 3 & $(7.3)$ & & & \\
\hline & Part-time & 6 & $(14.6)$ & & & \\
\hline & Unemployed & 5 & $(12.2)$ & & & \\
\hline & Disability pensioner & 10 & $(24.4)$ & & & \\
\hline & Retired & 17 & $(41.5)$ & & & \\
\hline \multirow[t]{3}{*}{ Nationality: } & Swiss & 28 & $(68.3)$ & & & \\
\hline & Other European countries & 10 & $(24.4)$ & & & \\
\hline & Latin America & 3 & $(7.3)$ & & & \\
\hline \multirow[t]{4}{*}{ Marital status: } & Single & 6 & $(14.6)$ & & & \\
\hline & Married/ common law & 19 & $(46.3)$ & & & \\
\hline & Divorced/ separated & 11 & $(26.8)$ & & & \\
\hline & Widowed & 5 & $(12.2)$ & & & \\
\hline \multirow[t]{2}{*}{ Religion: } & Christian & 34 & (82.9) & & & \\
\hline & Other & 7 & $(17.1)$ & & & \\
\hline Age (years): & & & & 57.78 & (11.6) & $30-75$ \\
\hline \multirow[t]{5}{*}{ Number of children } & 0 & 12 & (29.3) & & & \\
\hline & 1 & 11 & $(26.8)$ & 32.7 & $(9.3)$ & $8-47$ \\
\hline & 2 & 11 & $(26.8)$ & 30 & $(9.3)$ & $15-46$ \\
\hline & 3 & 3 & (7.3) & & & \\
\hline & 4 & 4 & $(9.8)$ & 17.3 & $(7.5)$ & $10-25$ \\
\hline
\end{tabular}




\section{Table 2. Acceptability of the intervention ( $n=36$ patients)}

\begin{tabular}{|c|c|c|c|}
\hline & & Patient ratings* & (SD) \\
\hline During the meeting, the questions & Easy to understand & 4.4 & $(0.6)$ \\
\hline \multirow[t]{3}{*}{ were: } & Distressing & 2.5 & (1.3) \\
\hline & Intrusive & 2.2 & (1.4) \\
\hline & Relevant & 3.9 & $(1.3)$ \\
\hline \multirow[t]{3}{*}{ Scheduling: } & Difficult to find the time & 1.9 & $(1.3)$ \\
\hline & Sufficient sessions & 4.5 & $(0.6)$ \\
\hline & Adequate interval between the sessions & 4.4 & $(0.8)$ \\
\hline \multirow[t]{2}{*}{ The location was: } & Adequate & 4.4 & $(0.7)$ \\
\hline & Comfortable & 4.5 & $(0.6)$ \\
\hline \multirow[t]{2}{*}{ The booklet was: } & Congruent with my words & 4.7 & $(0.4)$ \\
\hline & I appreciated the presentation & 4.8 & $(0.4)$ \\
\hline \multirow[t]{3}{*}{ Overall: } & The intervention was helpful & 4.3 & $(0.7)$ \\
\hline & I am satisfied with the intervention & 4.6 & $(0.5)$ \\
\hline & I would recommend it to others & 4.5 & $(0.6)$ \\
\hline
\end{tabular}

*1 = strongly disagree, 2 = disagree, $3=$ neither agree nor disagree, $4=$ agree, and $5=$ strongly agree

Table 3: Differences in the total PDI score and subdimensions, at baseline and after completion of the study ( $\mathrm{n}=36$ patients)

\begin{tabular}{|c|c|c|c|c|c|c|c|c|}
\hline \multirow{2}{*}{$\begin{array}{l}\text { Dignity } \\
\text { PDI total score }\end{array}$} & \multicolumn{2}{|c|}{$\begin{array}{c}\text { Baseline } \\
\text { Median (SD) }\end{array}$} & \multirow{2}{*}{$\begin{array}{c}\text { Range } \\
25-78\end{array}$} & \multicolumn{2}{|c|}{$\begin{array}{r}\text { Study completion } \\
\text { Median (SD) }\end{array}$} & \multirow{2}{*}{$\begin{array}{l}\text { Range } \\
25-92\end{array}$} & \multirow{2}{*}{$\begin{array}{r}z^{\mathrm{a}} \\
-1.90\end{array}$} & \multirow{2}{*}{$\begin{array}{r}p \text {-value } \\
0.057\end{array}$} \\
\hline & 36 & $(12.97)$ & & 38 & $(14.04)$ & & & \\
\hline Symptom distress & 9 & $(4.29)$ & $5-23$ & 10 & $(4.92)$ & $6-27$ & -1.68 & 0.093 \\
\hline Existential distress & 8 & (3.72) & $6-21$ & 9.5 & $(4.70)$ & $6-30$ & -1.84 & 0.065 \\
\hline Level of independence & 3 & $(1.57)$ & $3-10$ & 3 & $(1.61)$ & $3-11$ & -0.28 & 0.773 \\
\hline Peace of mind & 4 & $(1.56)$ & $3-10$ & 4.5 & (2.29) & $3-11$ & -1.19 & 0.231 \\
\hline Social support & 3 & $(0.78)$ & $3-6$ & 3 & $(0.74)$ & $3-7$ & -0.85 & 0.396 \\
\hline
\end{tabular}




\section{Table4: Differences in the PDI item scores between baseline and after completion of the study ( $n=36$ patients)}

\begin{tabular}{|c|c|c|c|c|c|c|}
\hline & PDI questions & Baseline & Study completion & $95 \% \mathrm{Cl}$ & Paired t-test & $p$-value \\
\hline 1. & Not being able to carry out tasks associated with daily living & $1.25(0.73)$ & $1.30(0.78)$ & {$[-0.34-0.23]$} & 0.38 & 0.701 \\
\hline 2. & Not being able to attend to my bodily functions independently & $1.05(0.23)$ & $1.08(0.50)$ & {$[-0.15-0.09]$} & 0.44 & 0.661 \\
\hline 3. & Experiencing physically distressing symptoms & $2.02(1.02)$ & $2.25(1.27)$ & {$[-0.63-0.19]$} & 1.09 & 0.282 \\
\hline 4. & Feeling that how I look to others has changed significantly. & $1.54(0.78)$ & $1.71(1.01)$ & {$[-0.61-0.27]$} & 0.78 & 0.439 \\
\hline 5. & Feeling depressed & $1.41(0.85)$ & $1.55(0.92)$ & {$[-0.54-0.24]$} & 0.75 & 0.454 \\
\hline 6. & Feeling anxious & $1.55(0.93)$ & $1.72(1.08)$ & {$[-0.54-0.20]$} & 0.90 & 0.373 \\
\hline 7. & Feeling uncertain about my health and health care & $1.50(0.77)$ & $1.77(1.07)$ & {$[-0.60-0.05]$} & 1.71 & 0.096 \\
\hline 8. & Worrying about my future & $1.94(0.95)$ & $2.19(1.32)$ & {$[0.56-0.06]$} & 1.60 & 0.119 \\
\hline 9. & Not being able to think clearly & $1.38(0.72)$ & $1.22(0.72)$ & {$[-0.08-0.41]$} & 1.35 & 0.183 \\
\hline 10. & Not being able to continue with my usual routines & $1.94(1.05)$ & $2.14(1.21)$ & {$[-0.61-0.21]$} & 0.98 & 0.334 \\
\hline 11. & Feeling like I am no longer who I was & $1.73(0.96)$ & 2.44 (1.39) & {$[-1.16-0.24]$} & 3.13 & $0.004^{*}$ \\
\hline 12. & Not feeling worthwhile or valued & $1.41(0.90)$ & $1.50(1.08)$ & {$[-0.44-0.28]$} & 0.46 & 0.646 \\
\hline 13. & Not being able to carry out important roles & $1.61(0.95)$ & $1.61(1.23)$ & {$[-0.50-0.50]$} & 0.00 & 1.000 \\
\hline 14. & Feeling that life no longer has meaning or purpose & $1.36(0.96)$ & $1.44(0.87)$ & {$[-0.45-0.29]$} & 0.45 & 0.654 \\
\hline 15. & Feeling that I have not made a meaningful and/or lasting contribution in my life & $1.48(0.95)$ & $1.88(1.20)$ & {$[-0.87-0.07]$} & 1.71 & 0.095 \\
\hline 16. & Feeling that I have 'unfinished business' & $1.86(0.83)$ & $2.05(1.24)$ & {$[-0.56-0.17]$} & 1.07 & 0.292 \\
\hline 17. & Concern that my spiritual life is not meaningful & $1.13(0.42)$ & $1.05(0.23)$ & {$[-0.06-0.23]$} & 1.13 & 0.263 \\
\hline 18. & Feeling that I am a burden to others & $1.34(0.59)$ & $1.54(0.91)$ & {$[-0.44-0.04]$} & 1.64 & 0.109 \\
\hline 19. & Feeling that I don't have control over my life & $1.67(0.91)$ & $1.50(0.70)$ & {$[-0.08-0.37]$} & 1.30 & 0.201 \\
\hline 20. & Feeling that my health and care needs have reduced my privacy & $1.44(0.80)$ & $1.52(0.97)$ & {$[-0.34-0.17]$} & 0.64 & 0.520 \\
\hline
\end{tabular}




\begin{tabular}{|c|c|c|c|c|c|c|}
\hline 21. Not feeling supported by my community of friends and family & $1.02(0.16)$ & 1.20 & $(0.75)$ & {$[-0.44-0.09]$} & 1.29 & 0.205 \\
\hline 22. Not feeling supported by my health care providers & $1.19(0.46)$ & 1.00 & $(0.00)$ & {$[0.03-0.35]$} & 2.49 & $0.017^{*}$ \\
\hline 23. Feeling like I am no longer able to mentally cope with challenges to my health & $1.30(0.66)$ & 1.41 & $(0.99)$ & {$[-0.30-0.08]$} & 1.16 & 0.254 \\
\hline 24. Not being able to accept the way things are & $1.27(0.70)$ & 1.41 & $(1.07)$ & {$[-0.35-0.77]$} & 1.30 & 0.201 \\
\hline 25. Not being treated with respect or understanding by others & $1.13(0.54)$ & 1.00 & $(0.00)$ & {$[-0.04-0.32]$} & 1.53 & 0.134 \\
\hline
\end{tabular}

The data are means (SD). A score of 1 indicates that the item was not a problem, 2 a slight problem, 3 a problem, 4 a major problem, and 5 an overwhelming problem. 
Table 5: Differences in the means (PTG and SWLS) before and after the intervention $(n=35)$

\begin{tabular}{|c|c|c|c|c|c|c|c|}
\hline \multirow[b]{2}{*}{ PTGI - total } & \multicolumn{2}{|c|}{$\begin{array}{l}\text { Baseline } \\
\text { Mean (SD) }\end{array}$} & \multicolumn{2}{|c|}{$\begin{array}{l}\text { Study completion } \\
\text { Mean (SD) }\end{array}$} & \multirow{2}{*}{$\begin{array}{c}95 \% \mathrm{Cl} \\
{[-9.76-8.11]}\end{array}$} & \multirow{2}{*}{$\begin{array}{c}\begin{array}{c}\text { Paired } \\
\text { t-test }\end{array} \\
-0.18\end{array}$} & \multirow{2}{*}{$\begin{array}{r}p \text {-value } \\
0.852\end{array}$} \\
\hline & 78.17 & $(24.64)$ & 79.00 & $(24.00)$ & & & \\
\hline Relationships with others & 28.60 & $(8.72)$ & 29.68 & $(8.09)$ & {$[-4.45-2.28]$} & -0.65 & 0.517 \\
\hline New opportunities & 15.74 & $(8.24)$ & 15.85 & $(8.08)$ & {$[-2.53-2.31]$} & -0.96 & 0.924 \\
\hline Personal strength & 15.94 & $(5.46)$ & 15.08 & $(5.79)$ & {$[-1.38-3.10]$} & -0.77 & 0.443 \\
\hline Spiritual changes & 5.48 & $(3.43)$ & 5.68 & $(3.61)$ & {$[-1.41-1.01]$} & -0.33 & 0.740 \\
\hline Appreciation of life & 12.40 & $(3.75)$ & 12.68 & $(3.66)$ & {$[-1.73-1.16]$} & -0.39 & 0.692 \\
\hline SWLS - Satisfaction with life & 25.94 & (6.19) & 25.97 & $(7.58)$ & {$[-2.88-2.82]$} & 0.21 & 0.983 \\
\hline
\end{tabular}




\section{Figures}

Figure 1. Venn diagram

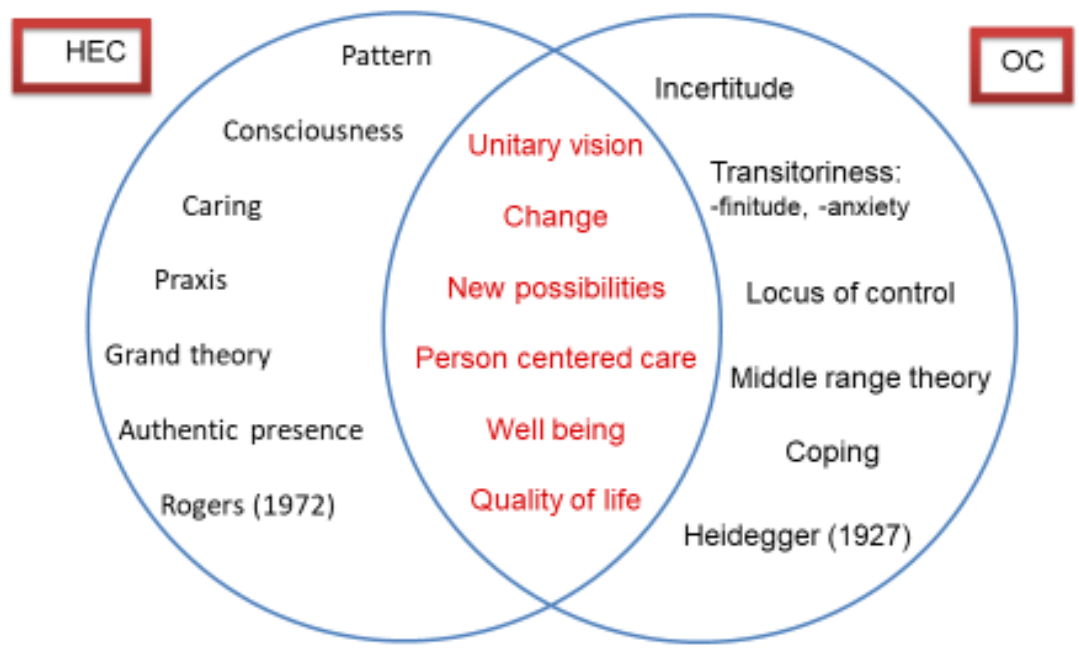

Figure 2: Description of Revie $\bigoplus$

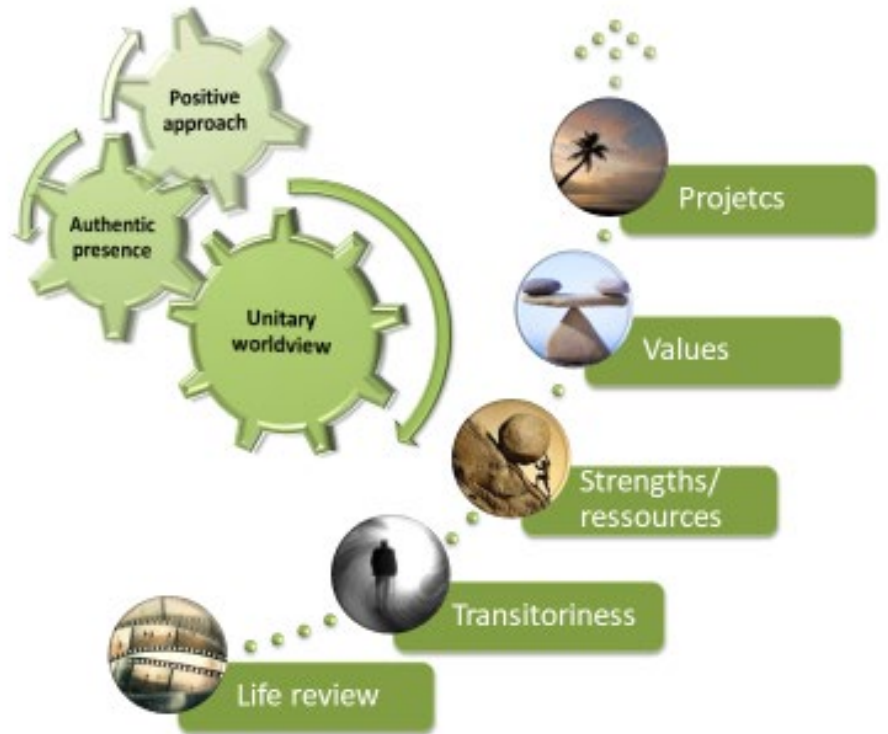

Session1: $60 \mathrm{~min}$

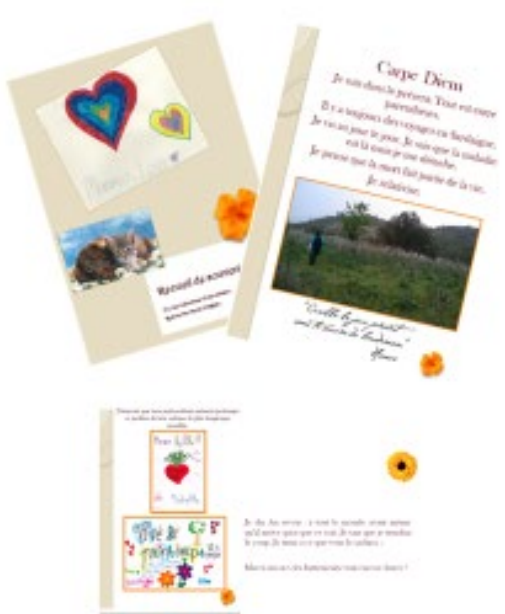

Session 2: $30 \mathrm{~min}$ 
Figure 3: Study procedure for patients

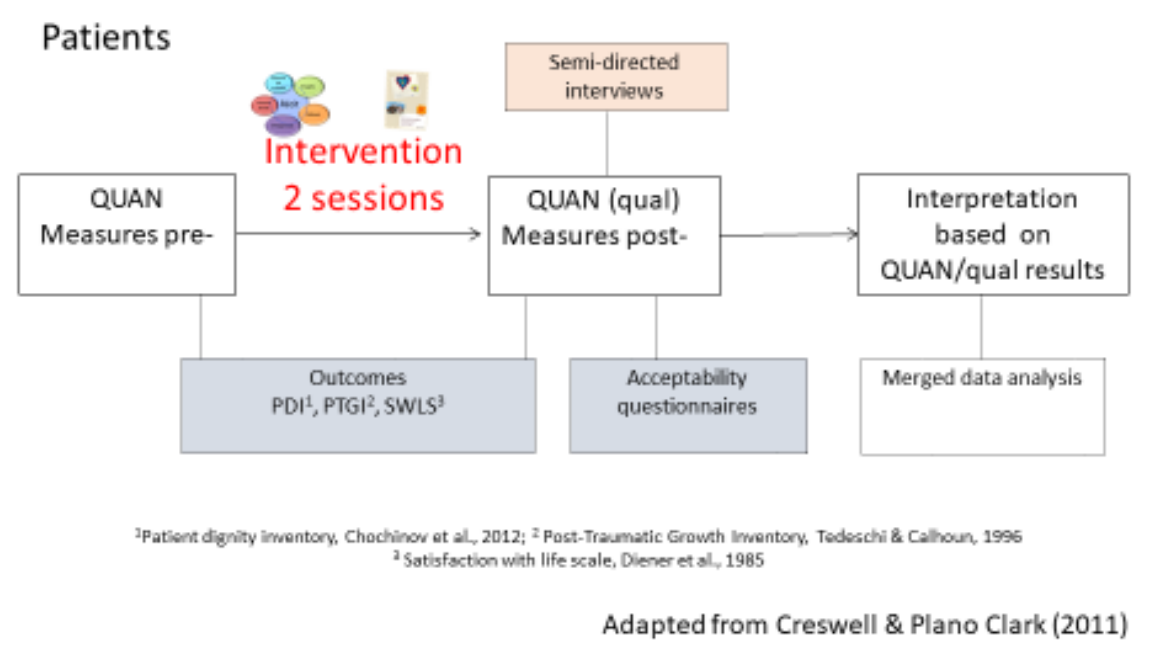

Figure 4: Study procedure for nurses

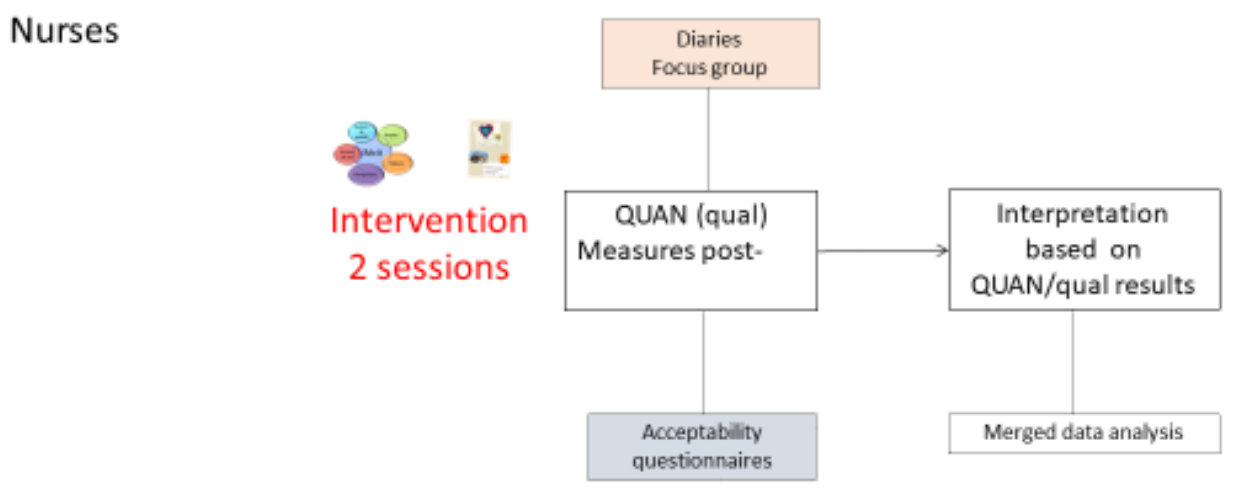

Adapted from Creswell \& Plano Clark (2011) 